\title{
eCOti
DiAno
}

Revista Mídia e Cotidiano

ISSN: 2178-602X

Artigo Seção Temática

Volume 14, Número 2, maio-ago. de 2020

Submetido em: 28/02/2020

Aprovado em: 06/05/2020

\section{Por carreteras secundárias: reflexões sobre o reporterismo a partir da narrativa de Bru Rovira sobre a cotidianidade dos anônimos}

\section{Via secondary roads: the reflection on reporterism based on Bru Rovira's narratives on the everyday lives of anonymous people}

\author{
Mauro de SOUZA VENTURA ${ }^{1}$ \\ Tayane AIDAR ABIB ${ }^{2}$
}

\begin{abstract}
Resumo
Este artigo investiga a reportagem enquanto método jornalístico por excelência, para além de gênero possível ao exercício profissional. Discute, neste sentido, os três procedimentos característicos à dinâmica do reporterismo - observação atenta, entrevista dialogal e experiência-vivência (VARGAS, 2017), desde um prisma de intersubjetividade e em entrecruzamento com princípios do jornalismo literário, tomando a narrativa de Bru Rovira como caso exemplar para a reflexão. A partir de uma análise interpretativa de sua obra Solo pido un poco de belleza (2016), que recompila registros sobre o cotidiano de personagens anônimos de Barcelona, evidencia em sua predileção noticiosa por temas secundários à cobertura hegemônica um terreno fértil para tessituras autorais, que colocam em relevo a trama singular e coletiva, a partir de histórias de vida.
\end{abstract}

Palavras-chave: Jornalismo Literário. Reportagem. Cotidiano. Bru Rovira.

\begin{abstract}
This article investigates reporting as a journalistic method par excellence, moving beyond the concept of textual genre. In this sense, it discusses the three procedures that characterize the dynamics of reporterism - attentive observation, dialogical interview and immersive experience (VARGAS, 2017). These draw from a perspective of intersubjectivity and from the intersection with principles of literary journalism, taking Bru Rovira's narrative as a case for reflection. Based on an interpretative analysis of his book Solo pido un poco de belleza (2016), which compiles records about the daily lives of anonymous people in Barcelona, his predilection for themes that are secondary to the

\footnotetext{
${ }^{1}$ Professor adjunto do Departamento de Comunicação Social da Universidade Estadual Paulista (Unesp). Livre-Docente em Jornalismo. Doutor em Teoria Literária e Literatura Comparada pela Universidade de São Paulo (USP). E-mail: ms.ventura@unesp.br. ORCID: 0000-0002-5557-228X.

2 Mestre e Doutoranda em Comunicação pela Universidade Estadual Paulista (Unesp). Bolsista de Doutorado da Fundação de Amparo à Pesquisa do Estado de São Paulo (FAPESP). E-mail: tayane.abib@unesp.br. ORCID: 0000-0003-2110-6640.
} 
hegemonic coverage highlights a fertile ground for authorial writings, which reveal singular and collective plots based on life stories.

Keywords: Literary Journalism. Reporting. Everyday life. Bru Rovira.

\section{Introdução}

Inscrita em plano propositivo, a reflexão que aqui se desenvolve assume também contornos de reivindicação: reconhecer o valor da reportagem enquanto dinâmica por excelência da profissão jornalística, destacando o fator humano como elemento mobilizador de práticas com tratamento narrativo distinto ao modelo informativo hegemônico. Em que pese um contexto produtivo marcado por constrangimentos econômicos e organizacionais, onde o investimento em coberturas de fôlego é escasso, o presente estudo reafirma uma predileção por tessituras autorais e complexas intersubjetivas em seus processos convencionalmente técnicos - para contar as histórias do tempo presente.

Artificialmente, o jornalismo tradicional, escreve Edvaldo Pereira Lima (2009, p. 358), esqueceu-se da propensão humana a narrar histórias, e acabou estruturando seu "discurso de modo considerado por muito tempo lógico, racional e objetivo. Pelo exagero, o que se gerou foi um modo de comunicação social muitas vezes asséptico, que o leitor logo esquece”. A acepção de reportagem como modus operandi (VARGAS, 2017), mais que gênero jornalístico, que se está a enfatizar aqui trabalha com o protagonismo das atitudes afetivas e das intuições estéticas, no plano da captação dos fatos, justamente em via de contraponto aos esquematismos pré-pautados (LAGE, 2005). Articula, neste sentido, procedimentos de apuração, entrevista e redação que, circunscritos pelo eixo da alteridade e em entrecruzamento com os princípios de humanização e imersão do jornalismo literário, configuram mediações atentas e dialogais, capazes de transitar pelos enredos singulares das tramas comuns.

Se os movimentos narrativos experimentais tiveram seu esplendor nos anos 1960, com o desenvolvimento de uma espécie de excitação artística no jornalismo, o momento atual pede, acredita-se, a retomada de um interesse em discutir dispositivos, 


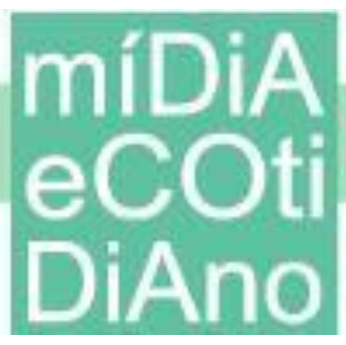

desde o âmbito da produção, que coloquem em relevo a perspectiva autoral tão cara aos registros que, contrariando o caráter descartável das notícias, perduram.

Tomamos a narrativa do jornalista catalão Bru Rovira como caso exemplar neste estudo. Da geração de profissionais que viveu o chamado tardo-franquismo espanhol (1969-1975), Rovira reúne, em sua trajetória, elementos da escola de Ryszard Kapuscinski e do novo jornalismo norte-americano (WOLFE, 2005), tendo se especializado, como repórter humanista, em coberturas de tema social e internacional. Por uma predileção noticiosa aos personagens anônimos, a cotidianidade converteu-se em seu território de atuação e fez do ritmo dos dias a temporalidade-chave das histórias contadas. Em lugar de rotina esvaída de sentidos, o dia-a-dia que tradicionalmente não desperta os holofotes da imprensa ganhou contornos de autenticidade, fantasia e resistência a partir de seu reporterismo. E as carreteras secundárias tornaram-se as incursões principais de sua dinâmica interessada em sublinhar a beleza do comum.

Tendo como ponto de partida a tessitura sobre a cotidianidade de personagens anônimos, portanto, inscrita no livro Solo pido un poco de belleza (2016), que reúne textos de Bru Rovira sobre um grupo de ex-alcoolatras de Barcelona, publicados originalmente no diário espanhol La Vanguardia, entre os anos 2004 a 2007, desenvolvemos reflexões que mobilizam jornalismo literário e filosofia, especificamente em seus princípios de humanização e imersão (LIMA, 2009), mirada atenta (ESQUIROL, 2006) e experiência dialogal (BUBER, 1979; GADAMER, 2002), em favor do que se designa reporterismo (VARGAS, 2017).

\section{Entrecruzamentos em favor do reporterismo}

"Se você ficar com vontade de ler mais ‘jornalismo literário', de 'não-ficção', ou que nome tenha uma reportagem bem apurada e apresentada com texto de qualidade, infelizmente [...] não há o que indicar na banca mais próxima de sua casa", escreve Joaquim Ferreira dos Santos, no posfácio para o livro Radical chique e o Novo Jornalismo, de Tom Wolfe (2005, p. 243), assumindo um tom crítico, que é também alerta: a reportagem especial está fora de moda. Aqueles registros marcadamente autorais, experimentais em recursos narrativos e com consistente trabalho de investigação, que "berravam no ouvido do leitor: fique aqui" (WOLFE, 2005, p. 30), nos anos 1960, 


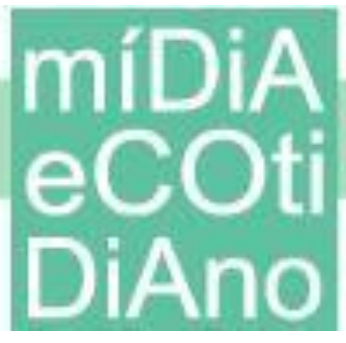

inspirados no realismo inglês do século XVIII e na literatura de viagem do começo do XIX, já não têm espaço no cenário atual.

Nos últimos anos, as matérias ficaram mais curtas, as redações, menores e a aposta dos meios por conteúdo exclusivo se enfraqueceu, colocando em risco a forma que até hoje é associada a rigor e qualidade jornalísticos pelas competências que engendra. Porque a reportagem pode até ter entrado na história para ser mais um gênero - o gênero jornalístico destaque do século XX, conforme Raúl Osorio Vargas (2017) -, mas acabou por se consolidar como a metodologia mesma da profissão, ou o modus operandi por excelência referenciado quando se discute trabalho noticioso bem feito.

Para além de uma delimitação conceitual ou de categorização (SODRÉ e FERRARI, 1986; COIMBRA, 1993; LIMA, 1993; LAGE, 2005; VASCONCELOS, 2008), deste modo, que bem serve a intuitos pedagógicos e de compreensão sobre o estado da arte em questão, a reportagem configura um aparato narrativo que diz das atitudes e movimentos de um profissional que a assume como dinâmica complexa, a integrar “observação minuciosa, encontro com o Outro, e experiência-vivência a fim de compreender a eterna viagem do Humano Ser" (VARGAS, 2017, p.118, tradução nossa) ${ }^{3}$. Reportar, afinal, é portar consigo letras, vozes, vida: "é neologismo que implica hermenêutica, porque é arte de interpretação e de compreensão da vida em si mesma", complementa o investigador colombiano (VARGAS, 2017, p. 03, tradução nossa).

Não à toa, José Hamilton Ribeiro (1998, p. 113) inscreve a reportagem como "ato de amor, de ilusão, de crença no ser humano". Porque fundamenta-se primordialmente no fenômeno da relação com a alteridade, e cobra, ademais de noções técnicas e de estilo, "saber como se dirigir aos demais, como tratar com eles e compreendê-los" (KAPUSCINSKI, 2002, p. 38, tradução nossa). Os três processos aqui identificados como característicos ao reporterismo, portanto - observação atenta, encontro com o Outro e experiência-vivência -, conforme Vargas (2017), consistem em práticas que se atrelam pelas qualidades de um jornalista que reconhece depender dos

\footnotetext{
${ }^{3}$ Considerando o alto número de traduções presentes no texto, optou-se pela manutenção das citações somente na versão em português. Todas as traduções são de responsabilidade dos autores do artigo.
} 
outros. Aquele que não sabe compartilhar, enfatiza o historiador e repórter polaco Ryszard Kapuscinski (2003, p. 07), "dificilmente pode se dedicar a esta profissão".

Há, neste sentido, como espécie de componente-princípio e mobilizador do exercício de reportagem que se quer aqui resgatar, o fator humano. A atitude pessoal, ou mirada própria, do jornalista que, por saber-se implicado socialmente, reconhece o valor de tal tratamento narrativo para uma escritura comprometida. E lança mão dos cinco sentidos de que fala Kapuscinski (2003) - estar, ver, ouvir, compartilhar e pensar -, ou do ato presencial que defende Medina (2016, p.19), para colocar "o corpo em ação, e encontrar o Outro com suas histórias, seu ambiente e a saga coletiva".

O recurso por excelência para apreender o social que se manifesta na experiência é a observação. Não aquela que se limita a ver, mas que busca um olhar que é também vinculação. Josep María Esquirol (2006), filósofo catalão com estudos sobre alteridade que bem podem contribuir com a prática jornalística, designa um tal movimento de mirada atenta - atribuindo-lhe, ademais de uma dimensão cognitiva, um papel ético. Ainda que pareça parte das ações diárias dos indivíduos, a atenção não é frequente. Estamos a tratar pessoas e coisas a todo momento, mas tendemos a fazê-lo superficialmente, pontua Esquirol (2006, p. 14, tradução nossa), "seguindo pautas assumidas, na maioria das vezes, de forma acrítica".

O esforço da atenção não consiste em nenhuma contração muscular. Em lugar de flexibilidade e tensão, é esvaziamento. É preciso empreender um esvaziamento e um desapego com relação a si mesmo; suspender o pensamento para deixa-lo mais disponível e penetrável, liberar o lastro (pelo menos momentaneamente) de tudo o que nos acompanha e, deste modo, descentrar-nos, sair de nosso lugar (ESQUIROL, 2006, p. 77, tradução nossa).

Não basta, deste modo, estar presente, ou se fazer mais presente na vida dos outros: o mais importante é comprometer-se sob um esvaziamento de si e uma abertura aos demais. Quando associada à atenção, por isso, a mirada ganha na capacidade de vincular os sujeitos diretamente com as coisas, as pessoas e o mundo, de forma a se configurar como atitude ética de respeito, por coincidir precisamente com a proximidade. Desde aí a equivalência, no pensamento de Esquirol (2006, p. 58, tradução nossa), dos 


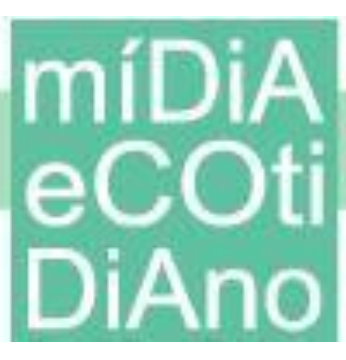

conceitos de respeito e mirada atenta, em que o cognoscitivo e o moral se atravessam "como um acercar-se que sabe guardar distância", isto é, sabe valorar a singularidade sem pretender assimilar ou reduzir o Outro.

A aproximação, neste sentido, fomenta nossa sensibilidade, aqui entendida como a capacidade de sermos afetados. Ao nos acercamos, entramos em áreas de influência e de irradiação com as coisas que estão ao nosso redor, implicamo-nos. De tal modo que podemos chegar a perceber que a ideia de 'grandeza' nada tem a ver com o impacto das dimensões aparentes, e sim com o caráter de extraordinário que somos capazes de atribuir mesmo aos elementos mais comuns.

“Não deveria ser necessário presenciar acontecimentos 'gigantescos', nem assistir a espetáculos esplêndidos para sentir admiração. O admirável reside igualmente no que nos rodeia em nossa vida cotidiana", é a defesa de Esquirol (2006, p. 87, tradução nossa), e uma ideia que também reside nas noções do romancista Georges Perec (2010), cuja proposição de um método infra-ordinário chama a atenção para uma descrição meticulosa, que captura as características de cada espaço e as formas de utilizá-lo, sublinhando a interação criadora entre sujeitos e entornos nas delimitações da vida diária.

“Anotar o que se vê, aquilo que seja importante”, sugere Perec (2010, p. 84), mas “sabemos ver o que é importante?”, o autor questiona, ao que se pode lançar a mesma provocação, em diretriz específica ao terreno da notícia. Tom Wolfe (2005, p. 55), ao defender o estreitamento da produção jornalística aos recursos do realismo social literário, também não nos deixa esquecer do valor do exercício de estranhamento, que coloca o indivíduo em posição de abertura e espanto ao rotineiro que o cerca. Tratar de registrar “gestos, hábitos, costumes, estilos de mobília, roupas, decoração [...] olhares, poses, estilos de andar e outros detalhes simbólicos do dia-a-dia que possam existir dentro de uma cena", sublinha o autor, como caminho para tecer narrativas que manifestam "a paixão intensa dos inocentes e dos descobridores".

Estamos anestesiados em busca de grandes projetos, de grandes momentos, de grandes personagens, dormindo "nossa vida em sono sem sonhos" (PEREC, 2004, p. 84), quando, na verdade, esses estão nos diminutos de nossas vidas, de nossos espaços, de nossos corpos. É tempo, por isso, alerta o escritor francês, de enfatizar não mais o exótico, mas o endótico, isto é, cercar as coisas comuns, entrar em sua intimidade e "trazê-las para 


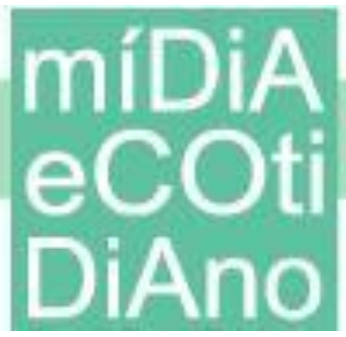

fora, arrancá-las da casca onde estão presas, dar-lhes um sentido, uma língua: que elas falem enfim do que é, do que somos". A camada do infra-ordinário em que Perec nos indica habitar dialoga, em última instância, com o sentido propositivo do reporterismo destacado por Vargas (2017): pode nos levar a compreender a humanidade que, de fato, nos constitui.

É interessante evidenciar como a atenção que deve acompanhar o olhar no procedimento da apuração, para uma vinculação com o contexto narrado e uma tessitura descritiva densa, é também condição de possibilidade, e consequência, do diálogo, na medida em que a boa conversação, assim como pede a abertura do sujeito, "aumenta e favorece a atenção sobre as coisas, ajudando-nos a ver melhor" (ESQUIROL, 2006, p. 95, tradução nossa).

Hans-Georg Gadamer (2002, p. 247) reflete sobre a experiência dialogal em ensaio que compõe sua obra Verdade e Método II, e que pode se estender ao campo jornalístico precisamente por enfatizar o potencial das interações que reconhecem o valor da humanidade de seus partícipes: "é só no diálogo que os homens podem encontrar-se e construir aquela espécie de comunhão onde cada qual continua sendo o mesmo para o outro porque ambos encontram o outro e encontram a si mesmos no outro”. Quando inscreve a entrevista jornalística como um braço da comunicação, Cremilda Medina (2008) põe precisamente em relevo tal procedimento em configuração de encontro com o Outro, para além de simples técnica.

Sua crítica ao dirigismo com que se executam os processos noticiosos busca liberar o profissional da camisa-de-força do questionário fechado, sublinhando "as possibilidades de enriquecimento informativo de uma entrevista de tipo aberto: o centro do diálogo se desloca para o entrevistado [...] e esta relação tem condições de fluir" (MEDINA, 2008, p. 11). Sob essa via, a entrevista assume feição compreensiva, interessada no conhecimento de sujeito a sujeito, aquele que deseja o "vínculo com a coisa que se aborda, com o outro, com a pluralidade dos outros, com o mundo" (SODRÉ, 2006, p. 68).

Está, portanto, diretamente relacionada ao princípio da humanização, a marca do Jornalismo Literário, na visão de Lima (2009), que se contrapõe à estereotipagem dos personagens e também contribui para uma visão complexa das situações retratadas, 


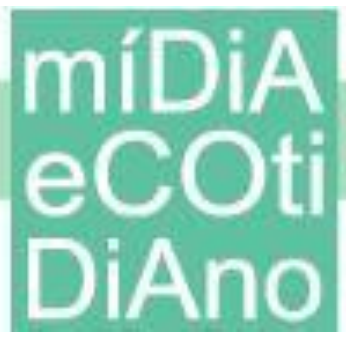

privilegiando uma abordagem multidimensional, aberta às múltiplas vozes e sentidos e orientada à "escuta e dialogia, à sensibilidade cultural e das identidades, à ação social interativa" (MEDINA, 2016, p.21)

Toda boa narrativa do real só se justifica se nela encontramos protagonistas e personagens humanos tratados com o devido cuidado, com a extensão necessária e com a lucidez equilibrada onde nem os endeusamos nem os vilipendiamos. Queremos antes de tudo descobrir o nosso semelhante em sua dimensão humana real, com suas virtudes e fraquezas, grandezas e limitações (LIMA, 2009, p. 359).

Assim, os processos de apuração e entrevista que se conjugam no exercício do reporterismo, sob as dinâmicas aqui destacadas, acabam por estruturar uma experiência de tipo vivência do jornalista no contexto reportado, isto é, convidam-no a participar e se envolver com a realidade de suas fontes. Trata-se de uma prática de imersão, também assinalada por Lima (2009, p. 373) como um mergulho no real, imprescindível para o jornalista literário "viver intensamente, de corpo e alma, a experiência de vida dos personagens".

Nesta etapa, tal qual destacam Mateus Passos e Romulo Orlandini (2008, p.86), "a pesquisa intensiva se soma à convivência com o tema e pessoas sobre quem se escreve", no acompanhamento de atividades rotineiras que acaba por abrir "novas e inusitadas possibilidades de captar, aprender, resgatar, narrar e compreender o ser humano em sua relação com o mundo" (VARGAS, 2017, p.43, tradução nossa). Em certo sentido, um tal processo aproxima-se do exercício etnográfico que, segundo Clifford Geertz (2008, p. 15, grifo nosso), busca um trabalho de campo "quase obsessivo", não interessado em apenas pensar "realista e concretamente sobre os outros e sua realidade", mas, principalmente, "criativa e imaginativamente com eles".

A capacidade criativa e imaginativa de que diz Geertz, em grande medida, atrelase à força dos sentidos humanos que só se mobilizam no plano da interpessoalidade. $\mathrm{O}$ tato é nosso autêntico ponto de encontro com o Outro, o paladar nos imprime memórias, e o olfato nos permite revestir com mais nuances as cenas que vivemos - integrados, todos esses recursos nos levam a experiências mais ricas em sutilezas e detalhes. Uma prática jornalística que se pretenda intersubjetiva e imersiva, então, necessita deixar de ordenar 


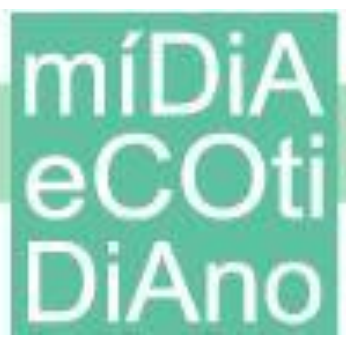

a realidade em função apenas do que se ouve e do que se vê, e implicar-se nos cenários para dar conta de sua complexidade.

Ao fim e a cabo, a questão que atravessa toda essa discussão versa sobre o reconhecimento da autoria jornalística. Se o manual positivista orienta sobre como esconder marcas subjetivas através das aspas, provas auxiliares e dados numéricos (TUCHMAN, 1993), o reporterismo que triangula pelos três procedimentos aqui mencionados, também entrelaçado a princípios do horizonte literário, destaca o valor de uma mediação que se assume autoral: quando vira autor, "desenvolve o contexto, cria sutilezas, inclui informações que dão às 'declarações' da fonte entrevistada uma abertura polissêmica" (MEDINA, 2008, p. 96).

Uma tal reflexão, neste sentido, assinala que a objetividade precisa ser superada não apenas no nível dos procedimentos noticiosos, quando conduz o aparato de captação dos fatos e as interações com as fontes, mas também em termos de escritura, transitando de modelos esquemáticos e engessados à fluidez complexa dos que assumem suas subjetividades. A matéria-prima estética, ensina Medina (2016, p. 277), "nasce no contato real. Não é preciso recorrer a fórmulas exitosas alheias". A montagem cênica das informações, deste modo, é um desafio intimamente integrado ao ato presencial do jornalista: desencadeia-se naturalmente e entrecruzando-se com as sinestesias de um profissional que experimenta as intensidades do ambiente e colhe, in locos as vozes que compõem a trama comum.

A partir dessa base teórica, buscaremos nos aprofundar sobre a prática de reportagem de Bru Rovira, apresentando os elementos que caracterizam sua trajetória profissional para, por fim, verificar a articulação dos dispositivos narrativos neste artigo sublinhados no plano da escritura de seus textos sobre personagens anônimos do bairro El Gótic, de Barcelona.

\section{A dinâmica narrativa de Bru Rovira}

Há uma biografia resumida, que apresenta a história de vida do jornalista em fatos datados e diretos, como pede o lead noticioso: Bru Rovira i Jarque nasceu em Barcelona, em 1955, trabalhou nas revistas espanholas Arreu, Primeras Noticias e La guia del ócio, e nos diários Tele/Exprés, El Noticiero Universal, Avui, La Vanguardia e 


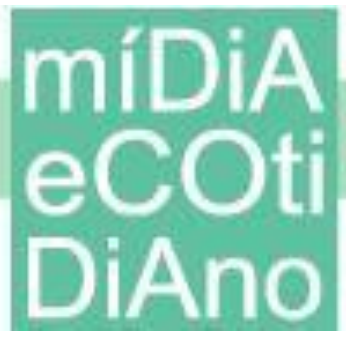

Ara. Atualmente, colabora com o programa A vivir que son dos días, transmitido aos sábados e domingos pela emissora Sociedad Española de Radiodifusión (SER), do conglomerado midiático PRISA. Sua trajetória profissional, no entanto, está marcada pelos 25 anos de atuação como repórter no jornal La Vanguardia, onde se destacou na cobertura de temas sociais e internacionais, e recebeu os prêmios Miguel Gil Moreno (2002) e Ortega y Gasset (2004) pelo conjunto de seu trabalho.

O exercício jornalístico que se está a defender neste artigo demanda, entretanto, um movimento de aproximação para ir além dos simples dados e alcançar a complexidade das histórias. Sendo assim, é importante começar destacando que Rovira fez escola em um ambiente de resistência e com figuras referências ao jornalismo catalão, como Josep María Huertas Clavería, Joaquín Ibarz e Manuel Vázquez Montalbán, que lutaram pela defesa da liberdade de imprensa durante o regime ditatorial de Francisco Franco (19391975), desde o Grup Democràtic de Periodistes. Inspirou-se também no trabalho de Ryszard Kapuscisnki, sobretudo em suas incursões pelo continente africano, fazendo da atitude de reportar a partir de personagens anônimos a peça chave de sua conduta profissional.

Da convicção do historiador e repórter polaco de que, "para se ter direito a explicar, é preciso ter um conhecimento direto, físico, emotivo, olfativo sobre aquilo que se fala" (KAPUSCINSKI, 2002, p. 15, tradução nossa), Rovira aprendeu o valor da observação às pequenas coisas. Identificar aqueles detalhes que significam aos sujeitos, conferem sentido ao seu cotidiano e acabam por conectar suas micro-realidades a dimensões sociopolíticas mais amplas.

Os elementos aparentemente simples carregam a potência de uma história, com sua vitalidade, suas contradições e fragilidades. O jornalismo, afinal, como ensina Kapuscinski (2002, p. 37, tradução nossa), é também ofício de emoções, já que "a fonte principal de nosso trabalho são 'os outros"”. E, para Rovira, é pelo escopo que atrela os diminutos às subjetividades humanas que somos capazes de alcançar a complexidade do real - como uma espécie de porta de entrada à compreensão das redes contextuais que formam a vida em sociedade.

Se o mundo pode ser explorado desde uma multiplicidade de rotas, Rovira elege adentrá-lo pelas vias secundarias. Investindo no caminho e sem se preocupar em acelerar 


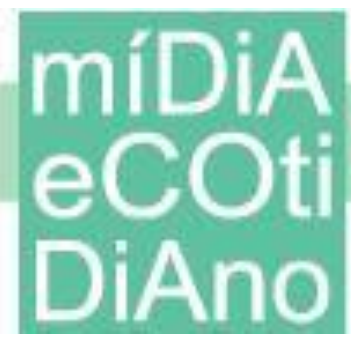

a chegada, é como se o repórter preferisse tomar as pistas vicinais, em alusão às viagens de automóvel que cruzam as regiões interioranas, assim disfrutando o percurso e dedicando interesse aos seus entornos. Aplicada ao jornalismo, essa dinâmica assume a configuração de uma prática contracorrente: diante de um processo de produção noticioso acomodado nas rotinas profissionais (TRAQUINA, 2005), manifesta-se como atitude vital de oposição às narrativas centradas nas figuras oficiais, sinalizando, portanto, para uma espécie de jornalismo de anti-poder.

$\mathrm{Na}$ ideia de carreteras secundarias está, portanto, a conduta propositiva do repórter catalão de resgatar o protagonismo de pessoas e temas marginalizados pelas coberturas midiáticas hegemônicas, de modo a convertê-los em peças centrais nas discussões acerca das problemáticas socioculturais. Aos tradicionais saberes de reconhecimento, procedimento e narração (TRAQUINA, 2005), que direcionam modelo informativo em função de critérios de noticiabilidade, predileção por fontes oficiais e redação em formatos de lead e pirâmide invertida (LAGE, 2005), a acepção de carreteras secundárias fundamenta possibilidades de coberturas de fôlego, onde o valor está na construção de sentidos tecida por cada sujeito, no compartir entre repórter e personagens, e na tomada de uma escritura que, antes de aplicar fórmulas, busca encontrar os pontos de cadência entre os acontecimentos, através de uma vinculação com seus contextos.

Trata-se de um modus operandi que Bru Rovira manifestou com potência e liberdade em seus anos de reporterismo para o jornal espanhol La Vanguardia, sobretudo no período em que contribuiu com as seções La Revista ${ }^{4}$ (1989-1997) e Carreteras Secundarias (2004-2007) do diário. Foi uma etapa, conforme relata Juan José Caballero, redator-chefe do diário de 1982 a 2009, em que havia um projeto editorial interessado em desenvolver "uma visão distinta das notícias, mais profundas, sob as chaves da reportagem e da narração" (2019, informação verbal ${ }^{5}$, tradução nossa). Uma aposta, em

\footnotetext{
${ }^{4}$ Criada em 03 de outubro de 1989, La Revista era uma seção de reportagens publicada diariamente, na cor salmão, nas duas páginas centrais do jornal La Vanguardia. Mais informações em: http://hemeroteca.lavanguardia.com/preview/1989/10/03/pagina-31/33083527/pdf.html

${ }^{5}$ Entrevista concedida aos autores em 04 de dezembro de 2019, como parte de projeto de pesquisa (FAPESP/processo 2018/23954-3) sobre a obra jornalística de Bru Rovira e a atuação da imprensa espanhola no período pós-franquismo.
} 


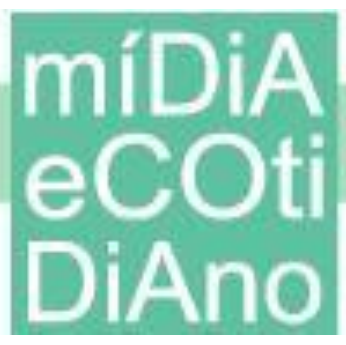

outras palavras, pela singularidade na escolha das pautas e um cuidado com o tratamento narrativo, na concretização do lema "ver, ouvir e contar", sobre o qual refletíamos antes.

Como membro da equipe de profissionais criada pelo La Vanguardia em sua reformulação gráfico-editorial de 1989, Rovira colaborou como repórter de temas sociais e enviado especial a países da Europa do Leste, da Ásia, da América Central e da África, narrando cenários de crise humanitária e conflitos, durante um período em que também desenvolvia experiências fotográficas - sozinho, ou com o fotógrafo brasileiro Sebastião Salgado.

Além de suas incursões internacionais, trabalhou em Barcelona reportando sobretudo na primeira década dos anos 2000 - anciãos e personagens anônimos da cidade. Em 2004, inclusive, passou a assinar os textos da seção do diário denominada Carreteras Secundárias, criada como sugestão sua, em que publicou as histórias de Vittorio e seus amigos - "el bando de los poetas", até 2007, e que posteriormente foram compiladas no livro Solo pido un poco de belleza (2016) - sobre as quais dedicamos atenção especial no tópico seguinte.

\section{Por carreteras secundarias: o reporterismo sobre a cotidianidade do homem comum}

A referida obra de Rovira configura-se como narrativa jornalística sobre a cotidianidade de personagens anônimos de Barcelona, especificamente de um grupo de ex alcoólatras do bairro El Gótic que, às quartas-feiras, encontrava-se no Centro de Serviços Sociais da Ciutat Vella para se ajudarem mutuamente. Vittorio, um antigo mercenário de guerras africanos, protagoniza com Ramón Pomar, Juan Benavente, Juan Carlos, José Antonio, Abdellah e Nordin os relatos que sustentam as reportagens publicadas, além de algumas passagens pelas histórias de Josefa, Ana Luisa e Alina mulheres que formavam parte de um grupo de leitura do mesmo centro social, onde coincidiam uma vez ao mês.

Judith, a assistente social do Centro, foi a porta de entrada de Rovira à essa relação, que durou quase quatro anos - período em que ele publicava os textos semanalmente no diário La Vanguardia -, sob uma mediação jornalística imersiva, em que repórter e personagens viviam experiências comuns no decorrer dos dias, não apenas no ambiente dos Serviços Sociais do bairro, mas também no bairro Arri, nos entornos do 
Correu Vell da cidade, onde se encontravam para tomar café da manhã juntos; ou no Hospital del Mar, quando visitavam Benavente, antigo legionário em Ceuta e Melilla, em recuperação após um derrame cerebral em uma noite de embriaguez; ou, ainda, nas margens da praia Barceloneta, nos dias de verão.

Também celebraram juntos o Natal de 2004, em um restaurante de um amigo do italiano Vittorio, na rua Ample. É interessante observar, neste ponto, o valor que Rovira atribui ao compartilhar das refeições em seus textos, e mesmo para compor o perfil dos personagens: nas escolhas dos salgados e cafés, nas mudanças e repetições dos itens do cardápio, identifica os gostos e humores de cada um, fundamentando uma apuração densa em detalhes e atenta às sensações que emanam quando o repórter mobiliza seus sentidos: "perceber o real pela escuta, pelo tato, pelo paladar, pela visão e pelo olfato", sugere Cremilda Medina (2008, p. 95), ao refletir sobre os afetos no jornalismo.

Brindamos pelos ausentes. Pela senhora Eulogía. Por Benavente, que seguia internado em uma residência com vista à montanha de Tibidabo, agora que já não mais poderia escalá-la. Brindamos pela senhora Teresa, que pagou a comida. Fantasiamos um pouco: talvez uma viagem todos juntos a Motserrat, disse Ramon. [...] Ainda que o Natal não tenha sido na casa de amigos, foi entre amigos. Um Natal em família, disse Vittorio (ROVIRA, 2016, p. 175, tradução nossa).

Em plano interacional, observa-se que as incursões narrativas do repórter ganham novos contornos ao atrelar o movimento da escuta que caracteriza a experiência dialogal à uma tomada de posição do mesmo enquanto interlocutor, isto é, partícipe do signo da relação (MEDINA, 2006), chamado a partilhar também suas vivências em um percurso que passa a tomar uma forma coletiva:

Ainda que eu tivesse ido à reunião para escutar o grupo, logo eles deixaram claro que, se eu quisesse escutá-los, também teria que falar. Ou falamos todos ou não fala ninguém, advertiu Vittorio, durante as apresentações. - Você conta uma história. Eu conto uma história. Eles contam uma história - disse agora o mercenário com um sorriso desafiante, provocando um coro de risadas entre o grupo (ROVIRA, 2016, p.27, tradução nossa). 
O relato manifesta, assim, os traços que perfilam os personagens no jogo das memórias e condutas que vão se desencadeando em cada encontro. Em tessitura não cronológica, Rovira conduz a escritura em função também do fluxo de consciência dos membros do grupo, explorando esteticamente os elementos do real e da fantasia que se entrelaçam no decorrer dos dias, de modo a apreender aquela carga mágica que, nas palavras de Michel Maffesoli (1984, p. 12), situa-se como "a pulsão irreprimível e misteriosa da vontade de viver".

Então, como se tivesse tido uma iluminação, Ramón levantou o olhar, exaltado: - Sabe o que eu queria? Pintar as montanhas de Montserrat! E viver no campo. Com um cachorro. Uma cabana de madeira, isso me encantaria, disse com os olhos iluminados. Uma cabana simples. E o amor de um animal. Um animal de tamanho médio. Quem sabe cultivar uma horta. Plantar tomates. Batatas. Alface. Cenoura. Só peço um pouco de beleza (ROVIRA, 2016, p.56-57, tradução nossa).

O imaginário, afinal, segundo Esquirol (2019, informação verbal ${ }^{6}$, tradução nossa), tem a função essencial de "criar espaços próximos, aquecidos, para resistir à intempérie existencial, ideológica [...] especialmente para nos proteger. Não é engano, é construção de sentidos". Em outras palavras, revela basicamente os intentos de cada um em dar forma a uma necessidade de amparo, e por isso ganha relevo na composição dos personagens do bando dos poetas. Tudo isso se viabiliza desde um movimento de valorização, por parte do repórter catalão, do plano da cotidianidade, espaço elegido pelo jornalismo de carreteras secundárias justamente para promover condutas sensíveis ao Outro e seus entornos sociais.

Na linha do pensamento de Esquirol (2005), o texto de Rovira enfatiza a autenticidade do ritmo dos dias e reconhece que o cotidiano, longe de homogeneidade, é, de fato, o horizonte de orientação de sentidos que os sujeitos compartilham. É onde se inscreve o mundo propriamente humano, "não como uma totalidade material, e sim como uma totalidade cultural - com as experiências, as relações humanas, as instituições e o

\footnotetext{
${ }^{6}$ Entrevista concedida aos autores em 09 de outubro de 2019, como parte de projeto de pesquisa (FAPESP/processo 2018/23954-3) sobre a obra jornalística de Bru Rovira e a atuação da imprensa espanhola no período pós-franquismo.
} 
poder, os sedimentos históricos e os símbolos culturais” (ESQUIROL, 2005, p. 20, tradução nossa).

Conforme Alfred Schutz (1979, p. 72), o mundo da vida cotidiana é um mundo intersubjetivo, comum a todos, que contém um estoque de experiências anteriores a ele, isto é, marcos de referência socioculturais que foram constituídos e organizados em outro tempo, e que funcionam como um código ou "conhecimento a mão" a nossas experiências atuais - e que nos recorda que o dia-a-dia não é somente acontecimento privado, mas espaço vivenciado e interpretado por outros, de modo a implicar afetações.

Há, neste sentido, uma dupla perspectiva que se entrecruza na concepção de cotidianidade e que bem se aplica ao exercício jornalístico que se está a tratar neste artigo: por um lado, a de um âmbito comum que nos estabelece em sentido similar e que faz com que nos vejamos de forma parecida e possamos coordenar nossos interesses; por outro, a de uma subjetividade particular "originalmente dada ao sujeito, a ele somente. Ele percebe o mesmo objeto que seu companheiro, mas com coloridos que dependem de seu determinado 'aqui' e seu fenomenal 'agora"” (SCHUTZ, 1979, p.161).

À dinâmica do reporterismo, a compreensão desses aspectos que constituem o mundo da vida representa a inscrição da cotidianidade como terreno fértil à tessitura de narrativas com motivações recíprocas, de experiências-vivências, mas desde a descoberta específica das significações particulares do Outro. Trata-se do reconhecimento do valor das pequenas coisas que compõem a rotina dos indivíduos, por perceber que, por trás da materialidade ou da inautenticidade de um uso, jogam criações de sentido e códigos intersubjetivos que vão para além das aparências.

Todos temos uma história, afirma Rovira (2019, informação verbal ${ }^{7}$, tradução nossa), que tem valor para ser notícia de primeira página, "a depender do talento do repórter para explicar algo" - que aqui enfatizamos como a atitude jornalística de dedicar uma mirada atenta ao cotidiano e o movimento da escuta no diálogo com os outros -: "porque todo mundo é movido pelo mesmo [...] e a grandeza de uma história é conseguir estabelecer identificação, mas ir além, abrindo portas para a compreensão do humano".

\footnotetext{
7 Entrevista concedida aos autores em 14 de dezembro de 2019, como parte de projeto de pesquisa (FAPESP/processo 2018/23954-3) sobre a obra jornalística de Bru Rovira e a atuação da imprensa espanhola no período pós-franquismo.
} 
Quando se trabalha desde as vias da humanização, acreditamos, tal qual prescreve o ideário formulado por Lima (2009) e a dinâmica do reporterismo alinhada à perspectiva intersubjetiva, a narrativa se inscreve como espaço potencial para o reconhecimento do Outro como Tu (BUBER, 1979). É este o eco que ressoa na obra aqui analisada, e é essa a mirada que sustenta a prática das carreteras secundárias.

\section{Considerações}

O percurso de investigação traçado neste artigo enquadrou a reportagem enquanto método jornalístico por excelência (VARGAS, 2017), para além de gênero possível ao exercício profissional. Dedicou especial interesse em discutir os três procedimentos característicos à dinâmica do reporterismo, desde um prisma de intersubjetividade e em entrecruzamento com princípios do jornalismo literário: a apuração como mirada atenta (ESQUIROL, 2006) e registro descritivo minucioso (WOLFE, 2005; PEREC, 2004), a entrevista como método dialogal (GADAMER, 2002) e via de humanização (LIMA, 2009), e o narrar como experiência-vivência ou prática de imersão (LIMA, 2009; GEERTZ, 2008), sob a argumentação de que é nessa triangulação que o jornalismo alcança contornos autorais que o diferem dos modelos esquemáticos hegemônicos.

A partir da obra Solo pido un poco de belleza (2016), do repórter catalão Bru Rovira, buscou-se sublinhar a presença de tais dispositivos como elementos centrais de uma prática que, ao narrar personagens anônimos de Barcelona, confere protagonismo à cotidianidade de homens comuns. Desvencilhando-se da lógica noticiosa tradicional, Rovira faz das carreteras secundárias território fecundo para a emergência de pautas que são singulares em suas abordagens centradas em histórias de vida, mas que ganham sentido universal ao tranversalizarem temáticas como o alcoolismo e a marginalidade social, assim promovendo a relação de identificação entre leitores e personagens, ademais do vínculo primeiro entre repórter e fontes.

O texto poroso às potencialidades literárias, afinal, tem a tarefa dupla de contar bem uma história e fomentar reflexões, trabalhando em ordem de temporalidade elástica e de resistência ao imediatismo da notícia. Não limitado ao relato pontual dos acontecimentos, assume a missão ambiciosa, nas palavras de Lima (2016, p. 03), “de tecer 


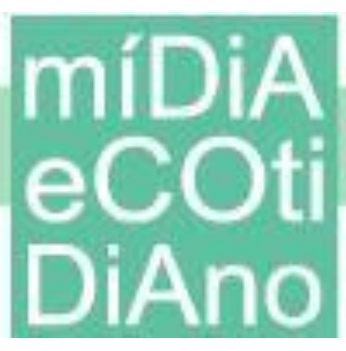

liames de compreensão abrangente, tendo sempre como eixo as histórias humanas que lhes dão dramaticidade, no sentido narrativo".

Pelo princípio da mediação imersiva, no convívio semanal com os personagens que durou três anos, Rovira fez de seus registros obras coletivas, tal qual escreve Kapuscinski (2003, p. 08, tradução nossa), apostando na amizade como caminho para a captação narrativa e na relação com o Outro como seu recurso fundante: "saber colocarse em contato, ganhar a sua confiança, conquistar certa empatia com ele”. Estabeleceu, assim, o vínculo que diz das grandes experiências, mas que soube reconhecer o valor dos detalhes - aquela dimensão do infra-ordinário, conforme Perec (2010), fazendo viver a polissemia do texto.

Por entre afetos e miradas complexas, deste modo, sua escritura expressou uma associação de rigor no trabalho de investigação e abertura criativa, que lhe permitiu transitar de suas subjetividades às rememorações e ilusões do "bando dos poetas". Revelou, neste sentido, que, em suma, apurar, escutar e mergulhar na vida de todos os dias é o que sustenta a qualidade do trato narrativo, e que a reportagem aliada a tais princípios encontra vias propícias para se revigorar.

\section{Agradecimentos}

Tayane Aidar Abib agradece à Fundação de Amparo à Pesquisa do Estado de São Paulo (FAPESP) pelas bolsas de Doutorado (Processo 2018/01541-9) e de Estágio de Pesquisa no Exterior (BEPE Processo 2018/23954-3).

\section{Referências}

BUBER, Martin. Eu e tu. 2. ed. rev. São Paulo: Cortez \& Moraes, 1979.

COIMBRA, Oswaldo. O texto da reportagem impressa. Um curso sobre a sua estrutura. São Paulo: Ática, 1993.

ESQUIROL, Josep María. El respeto o la mirada atenta. Barcelona: Gedisa Editorial, 2006.

ESQUIROL, Josep María. Uno mismo y los otros: de las experiencias existenciales a la interculturalidad. Barcelona: Herder Editorial,2005.

GADAMER, Hans-Georg. Verdade e Método II: complementos e índice. Petrópolis, RJ: Vozes, 2002.

GEERTZ, Clifford. A interpretação das culturas. Rio de Janeiro: LTC, 2008. 
KAPUSCINSKI, Ryszard. Los cinco sentidos del periodista. México: Fundación Nuevo Periodismo Iberoamericano, Fundación Proa, FCE, 2003.

KAPUSCINSKI, Ryszard. Los cínicos no sirven para este oficio: sobre el buen periodismo. Barcelona: Editorial Anagrama, 2002.

LAGE, Nilson. A reportagem: teoria e técnica de entrevista e pesquisa jornalística. 6. ed. Record, Rio de Janeiro, 2005.

LIMA, Edvaldo Pereira. O jornalismo literário e a academia no Brasil: fragmentos de uma história. Revista Famecos, Porto Alegre, v. 23, n. supl., p. 2-19, out. 2016.

LIMA, Edvaldo Pereira. Páginas ampliadas. O livro-reportagem como extensão do jornalismo e da literatura. 4. ed. Baureri: Manole, 2009.

LIMA, Edvaldo Pereira. O que é livro-reportagem. São Paulo: Brasiliense, 1993.

MAFFESOLI, Michel. A conquista do presente. Rio de Janeiro: Rocco, 1984.

MEDINA, Cremilda. Ato presencial: mistério e transformação. São Paulo: Casa da Serra, 2016.

MEDINA, Cremilda. O signo da relação: comunicação e pedagogia dos afetos. São Paulo: Paulus, 2006.

MEDINA, Cremilda. Entrevista: o diálogo possível. São Paulo: Ática, 2008.

PASSOS, Mateus; ORLANDINI, Romulo. Um modelo dissonante: caracterização e gêneros do jornalismo literário. Contracampo, Rio de Janeiro, n. 18, p.75-96, julho-dez 2008.

PEREC, Georges. Aproximações do quê? Alea, Rio de Janeiro, v. 12, n. 1, p. 178-180, janeirojunho 2010.

PEREC, Georges. Especies de espacios. Barcelona: Montesinos, 2004.

RIBEIRO, José Hamilton. In: DANTAS, Audálio (Org). Repórteres. São Paulo: Senac, 1998.

ROVIRA, Bru. Solo pido un poco de belleza. Barcelona: Ediciones B, 2016.

SCHUTZ, Alfred. Fenomenologia e Relações sociais. Rio de Janeiro: Zahar Editores,1979.

SODRÉ, Muniz; FERRARI, Maria Helena. Técnica de reportagem. Notas sobre a narrativa jornalística. 4. ed. São Paulo: Summus, 1986.

SODRÉ, Muniz. As estratégias sensíveis: afeto, mídia e política. Petrópolis: Vozes, 2006.

TRAQUINA, Nelson. Teorias do jornalismo: a tribo jornalística - uma comunidade interpretativa transnacional. Vol. 2. Florianópolis: Insular, 2005.

TUCHMAN, Gaye. A objectividade como ritual estratégico: uma análise das noções de objetividade dos jornalistas. In: TRAQUINA, Nelson (Org.). Jornalismo: questões, teorias e 'estórias'. Lisboa: Vega, 1993.

VARGAS, Raúl Hernando Osorio. El reportaje como metodología del periodismo: una polifonía de saberes. Medellín: Editorial Universidad de Antioquia, 2017.

VASCONCELOS, Frederico. Anatomia da reportagem: como investigar empresas, governos e tribunais. São Paulo: Publifolha, 2008.

WOLFE, Tom. Radical Chique e o Novo Jornalismo. São Paulo: Companhia das Letras, 2005. 